\title{
PENGGUNAAN ALAT DAN MESIN BESAR-BESAR DALAM PEMBANGUNAN HUTAN : KEUNTUNGAN, KERUGIAN DAN UPAYA MENGOPTIMALKANNYA
}

\author{
(The Use of Large Machineries and Equipment in Forest Development : \\ Advantages, Disadvantages and Optimization Efforts)
}

\author{
Oleh / By : \\ Djaban Tinambunan \& Yuniawati
}

\begin{abstract}
Machineries and equipment having power $50 \mathrm{HP}$ or more are categorized as large machineries and equipment. Most of machineries and equipment used in forest development in Indonesia have the power more than $50 \mathrm{HP}$ and, therefore, are belonging to large machineries and equipment group.

The use of large machineries and equipment in forest development in Indonesia has brought many advantages as well as disadvantages. In the future, in optimizing that use, it is necessary to critically analyse various aspect of large machineries and equipment operations such as technical, economic, social, environment, institution and human resources aspects, and then to manage the operations professionally.

Decision makers and practitioners in forestry development are required to master all aspect mentioned above and practice them in real operations in the field so that forest development could be running well with minimum negative impacts.
\end{abstract}

Keywords : Large machineries and equipment, forest development, advantages, disadvantages and optimization efforts.

\begin{abstract}
ABSTRAK
Alat dan mesin berkekuatan $50 \mathrm{HP}$ atau lebih masuk dalam kategori alat dan mesin besar. Oleh karena sebagian besar alat dan mesin dalam pembangunan hutan (alsinhut) di Indonesia berkekuatan di atas 50 HP maka mereka pun termasuk kategori alat dan mesin yang besar.

Penggunaan alsinhut yang besar-besar telah terbukti memberi banyak keuntungan, namun sekaligus juga membawa banyak kerugian yang sulit untuk diatasi. Oleh karena itu, untuk masa datang, upaya pengoptimalannya perlu diusahakan dengan cara melakukan analisa krisis terhadap berbagai aspek pengoperasian alsinhut besar tersebut seperti aspek-aspek teknis, ekonomi, sosial, lingkungan, kelembagaan dan sumberdaya manusia dan kemudian mengelola pengoperasiannya secara profesional.

Pengambil kebijakan dan pelaksana pembangunan hutan perlu memahami semua aspek pengoptimalan penggunaan alsinhut di atas dan merealisasikannya dalam praktek di lapangan agar pembangunan hutan dapat berjalan baik dengan dampak negatif yang minimal.
\end{abstract}

Kata kunci : Alat dan mesin besar, pembangunan hutan, keuntungan, kerugian dan pengoptimalan. 


\section{PENDAHULUAN}

Pembangunan hutan di Indonesia berkembang pesat sejak awal tahun 1970-an. Hal ini terlihat dari laju perkembangan jumlah pengusahaan hutan, luas kawasan hutan yang dikelola dan penyebaran perusahaan ke luar Pulau Jawa yang meningkat drastis.

Dalam pembangunan hutan tersebut, alat dan mesin yang digunakan pun mengalami perubahan drastis dari alat-alat yang tadinya sederhana dan beroperasi secara manual ke penggunaan alat dan mesin pembangunan hutan (alsinhut) modern yang besar-besar. Alsinhut yang besar-besar memang ternyata sangat efektif dalam pembangunan hutan di luar Pulau Jawa yang umumnya prasarananya hampir tidak ada, medannya berat dan hasil hutan (kayu) yang ditangani berukuran besar-besar.

Sejak awal, tampaknya para pelaksana pembangunan hutan hanya memperhitungkan aspek kebaikan alsinhut besar-besar tersebut. Perkembangan kesadaran lingkungan dan hasil penelitian di banyak negara membawa pemahaman baru bahwa alsinhut besar-besar tersebut mempunyai segi keburukan yang serius berupa kerusakan hutan dan lingkungan. Kerusakan yang ditimbulkan mempunyai dampak yang luas dan sulit untuk diperbaiki.

Dalam keadaan alsinhut besar-besar yang sudah banyak tersebar di lapangan dan digunakan dalam pembangunan hutan, sedang kerusakan yang mungkin ditimbulkannya merupakan masalah serius, maka perlu dicarikan jalan tengah berupa pengoptimalan pemanfaatan alsinhut besar-besar tersebut. Dengan demikian pembangunan hutan dapat berjalan secara efektif dan kerusakan yang ditimbulkannya dapat ditekan sekecil mungkin.

Dalam tulisan ini diuraikan secara singkat penggunaan alsinhut besar-besar dalam pembangunan hutan, berbagai kebaikan dan keburukannya serta upaya pengoptimalan pemanfaatannya dengan harapan agar para pengambil kebijakan dan pelaksana dapat memahami permasalahannya secara benar dan mampu mengatasinya sehingga alsinhut yang besar-besar yang telah dan akan ada dapat mendorong pembangunan kehutanana Indonesia dengan sebaikbaiknya.

\section{PENGERTIANALAT DAN MESIN BESAR DALAM PEMBANGUNAN HUTAN}

Mesin yang digunakan dalam pembangunan hutan di Indonesia sejak awal PELITA I terdiri dari berbagai merek, jenis dan tipe. Ukuran mesin biasanya ditentukan berdasarkan tenaganya dalam menggerakkan suatu alat yang disambungkan kepadanya. Dalam pertanian secara umum (termasuk kehutanan), tenaga mesin yang biasanya disebut traktor, digolongkan ke dalam 3 kelas (Soedjatmiko, 1974) yaitu mesin (traktor) kecil (kekuatan < $12 \mathrm{HP}$ ), mesin (traktor) sedang (kekuatan 12-50 HP) dan mesin (traktor) besar (tenaga > $50 \mathrm{HP}$ ). Mesin-mesin (traktor) yang digunakan dalam pembangunan hutan di Indonesia umumnya bertenaga di atas $50 \mathrm{HP}$ sehingga masuk ketegori mesin besar. Alat-alat yang didesain untuk menyertai mesin-mesin tersebut harus besar juga agar sesuai sehingga gabungan keduanya disebut alsinhut yang besar.

Untuk menyalurkan tenaga mesin-mesin tersebut dalam mengerjakan sesuatu dalam pembangunan hutan, dibuat alat-alat (implement) yang besar-besar juga karena pekerjaan yang ditangani juga berat-berat seperti mendorong tanah, menarik kayu, dan sebagainya. Alat-alat tersebut disambungkan ke mesin-mesin yang besar-besar juga sehingga terbentuk alat dan mesin pembangunan hutan (alsinhut) yang besar-besar. 
Cara menyambung alat ke mesin ada 4 macam (Brainer et al.,1955) yaitu : (1) Trailed implement, yaitu alat yang ditarik melalui satu titik gandeng (single hitch point) dimana berat alat tidak sepenuhnya dibebankan pada mesin; (2) Semi mounted implement, yaitu alat yang digandengkan pada traktor melalui sebatang as (hinge axis ) sehingga memberikan reaksi langsung pada kemudi traktor sedangkan berat alat ketika diangkat tidak sepenuhnya dibebankan pada traktor; (3)Tractor mounted implement, yaitu alat yang digandengkan pada traktor sedemikian rupa dan dikemudikan secara langsung oleh traktor dan pada posisi alat sedang diangkat beratnya sepenuhnya dibebankan pada traktor; dan (4) Self mechanics power, yaitu mesin penggerak merupakan bagian integral dari mesin itu sendiri.

Alsinhut yang biasa digunakan dewasa ini dapat dikemukakan untuk masing-masing tahap sebagai berikut:

1. Untuk penyaradan kayu digunakan mesin (traktor) berantai Komatsu D80 atau Caterpillar D7 atau merek lain sekelas itu. Komatsu D80 mempunyai tenaga $180 \mathrm{HP}$ dan berat 22,7 ton, Caterpillar D7 mempunyai tenaga $225 \mathrm{HP}$ dan berat 20,0 ton, sedang traktor beroda karet Caterpillar 518 mempunyai tenaga 130 HP dan berat 22,7 ton. Mesin-mesin ini di lengkapi alatalat berupa pisau (dozer blade) di depannya dan penggulung kabel (powered winch) beserta kabelnya di bagian belakangnya untuk mengikat dan menyarad kayu (Anonim, 1988 dan Anonim, tanpa tahun).

2. Untuk memuat dan membongkar kayu digunakan alsinhut seperti Zil crane loader (75 HP), Pay loader Kimco IH (80 HP), Crawler Caterpillar 977 (170 HP), Wheel loader Caterpillar 988 (325 HP) dan berbagai merek lain sekelas dengan itu (Sastrodimedjo et al.,1973; Sastrodimedjo et al.,1977; dan Sianturi dan Tinambunan, 1984).

3. Untuk pengangkutan digunakan truk biasa dengan tenaga antara 65-120 HP dan daya muat antara 8-20 $\mathrm{m}^{3}$ seperti truk-truk merek Ford Canada STW, Bedford STW, Hino, Nissan dan lainlain. Sebagian lagi menggunakan truk gandengan berukuran besar dengan tenaga bervariasi dari 80-550 HP dan daya muat antara 20-50 $\mathrm{m}^{3}$ seperti merek IH Loadstar, Mercedes, Isuzu TWD, Kenworth, Nissan, Berliet, Mack dan lain-lain.

4. Untuk pembuatan jalan hutan biasanya digunakan mesin-mesin yang sekelas dengan mesin pada penyaradan yaitu kelas Komatsu D80 dan Caterpillar D7. Untuk pekerjaan yang lebih berat, sering juga digunakan Caterpillar D8 dengan tenaga $270 \mathrm{HP}$ dan berat 22,2 ton.

Dari informasi di atas, jelaslah bahwa alsinhut yang digunakan di Indonesia termasuk kategori alat dan mesin yang berukuran besar-besar yang harganya tinggi serta biaya pemilikan dan pengoperasiannya (owning and operating costs) persatuan waktu adalah mahal. Oleh karena itu, penggunaan alat dan mesin tersebut harus melalui tahap perencanaan yang matang dan efisiensi waktu dan produktivitas tinggi agar penggunaannya tidak rugi dan gangguan lingkungan yang ditimbulkannya berada pada tingkat minimal.

\section{KEUNTUNGAN PENGGUNAAN ALSINHUT BESAR DALAM PEMBANGUNAN HUTAN}

Berdasarkan pengamatan perkembangan pembangunan hutan di Indonesia sejak PELITA I sampai sekarang, terlihat beberapa keuntungan (advantages) penggunaan alsinhut besar dalam pembangunan hutan tersebut, antara lain: 
1. Mampu menangani produk (kayu) dalam jumlah besar

Produksi kayu bulat Indonesia sejak PELITA I mencapai jumlah yang sangat besar yang mencapai puncaknya pada tahun 1988/1989 sebesar 28 juta $\mathrm{m}^{3}$ lebih (Departemen Kehutanan, 1990). Jumlah sebesar itu hanya dapat dicapai berkat penggunaan alsinhut besar-besar dalam operasi pemanenan hutan di luar Pulau Jawa.

2. Proses produksi cepat dan tepat waktu

Angkutan kayu ke industri pengolahan dan ekspor mempunyai jadwal yang ketat dan mencakup volume yang besar. Keadaan seperti itu selama ini dapat dilayani dengan menggunakan alsinhut yang besar-besar.

3. Mampu menangani kayu-kayu yang besar dan panjang

Kayu yang dipanen di hutan alam di luar Pulau Jawa biasanya panjang dan diameternya besar. Untuk menangani itu, mulai dari penyaradan, muat, pengangkutan sampai bongkar muatan digunakan alsinhut yang besar.

4. Mampu menghadapi medan operasi pembangunan hutan berat

Kegiatan pembangunan hutan, terutama di luar Pulau Jawa, di samping medannya berat, prasarananya pada awal PELITA I belum ada. Dengan menggunakan alsinhut besar, operasi pembangunan hutan seperti membuat jalan, gorong-gorong, jembatan dan berbagai bangunan hutan lainnya dapat dilaksanakan sesuai jadwal.

5. Membuka lapangan kerja

Penggunaan alsinhut dalam pembangunan hutan mampu meningkatkan kemampuan membangun tenaga kerja terdidik (skilled labour) untuk mengoperasikan berbagai alsinhut dan alat-alat pendukungnya.

6. Bisnis suku cadang dan bahan pendukung berkembang

Pengoperasian banyak alsinhut membutuhkan banyak suku cadang, bahan bakar, oli dan sebagainya. Kesemuanya itu membuka kesempatan bisnis bagi masyarakat sehingga mampu meningkatkan kemampuan teknis maupun ekonominya.

7. Meningkatkan devisa negara

Berkembangnya penggunaan alsinhut besar sejak PELITAI mampu meningkatkan produk kayu secara drastis untuk diekspor. Untuk itu pemerintah Indonesia mendapat devisa yang besar dari sektor kehutanan.

8. Meningkatkan keterampilan pekerja

Dengan banyaknya alsinhut besar yang digunakan telah terdidik/terlatih benyak tenaga kerja Indonesia yang terampil dalam mengoperasikan, mereparasi dan memelihara alat-alat berat. Potensi ini merupakan modal penting untuk pembangunan di masa datang.

9. Pembukaan wilayah berjalan pesat

Penggunaan alsinhut besar selama ini dalam operasi kehutanan telah membuka daerah-daerah di luar Pulau Jawa yang sebelumnya terisolir akibat tidak adanya prasarana angkutan. Sekarang ini hampir semua daerah di luar Pulau Jawa telah terbuka dan akibatnya kegiatan ekonomi 
berkembang sampai ke pelosok-pelosok.

\section{KERUGIAN PENGGUNAAN ALSINHUT BESAR DALAM PEMBANGUNAN HUTAN}

Dalam pembangunan hutan di Indonesia selama ini terlihat bahwa penggunaan alsinhut besar-besar, di samping memberikan keuntungan, juga menimbulkan kerugian (disadvantages) yang besar, antara lain :

\section{Biaya produksi tinggi}

Alsinhut yang besar mempunyai harga yang mahal, demikian juga biaya pemilikan dan pengoperasiannya tinggi. Memang diharapkan alsinhut yang besar mempunyai produktivitas besar juga untuk mengimbangi biaya tinggi di atas. Akan tetapi kenyataan menunjukkan bahwa biaya produksi alsinhut besar tetap saja tinggi. Sebagai contoh, rata-rata biaya penyaradan dengan kerbau di Jambi adalah Rp 4.400/ $\mathrm{m}^{3}$-hm (Dulsalam dan Sukadaryati, 2001), sedang penyaradan dengan traktor Caterpillar D7 juga di Jambi adalah Rp 10.000/m $-\mathrm{hm}$ (Sukadaryati et al., 2002).

2. Kerusakan tegakan tinggal di hutan sangat tinggi

Pengoperasian alat-alat besar dalam pembangunan hutan menimbulkan kerusakan terhadap tegakan tinggal dengan skala yang cukup besar dan sebagian besar sulit atau tidak mungkin untuk diperbaiki. Hasil penelitian Suhartana (2003) menunjukkan bahwa rata-rata kerusakan tegakan tingggal yang diakibatkan penggunaan alsinhut pada kegiatan penyaradan terkendali berkisar $7,1-19,1 \%$ dan konvensional $11,8-40,4 \%$. Thaib (1985) mengatakan kerusakan tegakan tinggal pada sistem traktor bervariasi antara 3,8-50,8\% dengan rata-rata $23,9 \%$, sedangkan Dulsalam et al., (1989) mengatakan kerusakan tegakan tinggal akibat penyaradan menggunakan traktor pada kerapatan lebih kecil 150 pohon/ha adalah 16 pohon/ha, untuk kerapatan 150-199 pohon/ha kerusakan tegakan tinggal 28 pohon/ha dan pada kerapatan 200 pohon/ha memiliki kerusakan tegakan tinggal 39 pohon/ha. Dari beberapa hasil penelitian tersebut terlihat bahwa penggunaan traktor dalam penyaradan menimbulkan kerusakan tegakan tinggal yang besar.

\section{Luas keterbukaan tanah dan tajuk hutan yang tinggi}

Akibat penggunaan alsinhut besar di hutan alam luar Pulau Jawa keterbukaan tanah dan tajuk hutan sangat tinggi. Hal ini tentu mengganggu perkembangan pertumbuhan hutan pasca operasi alsinhut. Hasil penelitian Suhartana (2003) menunjukkan rata-rata keterbukaan tanah $11,2-139,0 \%$ pada penyaradan terkendali dan $15,2-57,5 \%$ pada penyaradan konvensional. Sedangkan Tinambunan (1998) mengatakan bahwa keterbukaan tanah pada pembuatan jalan utama saja berkisar dari 10.000-20.000 m²/ km dengan nilai rata-rata $19,120 \mathrm{~m}^{2} / \mathrm{km}$. Dengan asumsi $75 \%$ dari $75 \mathrm{HPH}$ di Kalimantan Barat membangun jalan utama masing-masing 5 $\mathrm{km} /$ tahun maka penambahan keterbukaan tanah pertahun di provinsi tersebut akan mencapai 537,75 ha/tahun.

4. Erosi tanah hutan tinggi

Banyak hasil penelitian menunjukkan bahwa akibat penggunaan alsinhut besar-besar dalam pembangunan hutan, terjadi erosi tanah hutan dengan tingkatan yang memprihatinkan. Hal tersebut dapat dilihat pada hasil beberapa penelitian antara lain : (1) Idris (1996) melaporkan bahwa penggunaan traktor Caterpillar D7G pada kemiringan jalan sarad antara $0-8 \%$ 
menyebabkan tanah tergeser rata-rata $0,06 \mathrm{~m} / \mathrm{m}$ panjang jalan sarad atau 0,061 ton $/ \mathrm{m}^{2}$ total erosi. Akibat penggunaan alsinhut untuk pembuatan jalan sarad masa 5 tahun sejak dibuat, erosi adalah 388 ton/ha; (2) Frederiksen (1970) pada tahun 1960-1968 mengemukakan bahwa rata-rata kehilangan sedimen tiap tahun dari areal hutan yang ditebang secara patch-cut dengan pembangunan jalan hutan adalah 30,8 ton/ha, sedangkan di areal tebang habis tanpa pembuatan jalan hutan terjadi sedimentasi sebesar 1,2 ton/ha.

\section{Pemadatan tanah hutan yang tinggi}

Pemadatan tanah terjadi karena adanya gaya tekan ke tanah dan getaran yang dihasilkan oleh traktor. Roda traktor bergerak di atas lapisan tanah (top soil) dan bekas roda terbentuk. Tanah dapat bergerak sebagian ke arah luar jejak roda dan sebagian lagi terpadatkan di bawah roda. Beberapa hasil penelitian mengenai pemadatan tanah hutan antara lain : (1) Hamzah (1978) dalam Manan (1994) mengatakan bahwa pada jalan sarad yang menggunakan traktor, pada kedalaman $0 \mathrm{~cm}$ menghasilkan berat jenis isi tanah yang tinggi yaitu $1,67 \mathrm{gr} / \mathrm{cm}^{3}$. Tingginya berat jenis isi tersebut menunjukkan telah terjadi pemadatan tanah yang tinggi pula; (2) Idris (1987) mengemukakan bahwa rata-rata pemadatan tanah sebagai akibat penyaradan dengan traktor berban ulat (crawler) merek Caterpillar D7G berkekuatan $200 \mathrm{HP}$ adalah 1,158 gr/ $\mathrm{cm}^{3}$; (3) Rahmawati (2002) melaporkan bahwa bertambahnya lintasan traktor pada jalan sarad mengakibatkan pemadatan tanah meningkat dari semula hanya $0,91 \mathrm{gr} / \mathrm{cm}^{3}$ menjadi 1,43 $\mathrm{gr} / \mathrm{cm}^{3}$; dan (4) Retnowati (2004) melaporkan bahwa penyaradan dengan Caterpillar D7G mengakibatkan pemadatan tanah meningkat rata-rata berkisar 0,03-0,33 gr/cc pada kedalaman tanah $0-20 \mathrm{~cm}$. Dari hasil penelitian tersebut jelas terlihat bahwa penggunaan alsinhut besarbesar menimbulkan dampak negatif berupa pemadatan tanah.

\section{Pencemaran air sungai tinggi}

Penggunaan alsinhut besar-besar terutama untuk kegiatan pembuatan jalan sarad, dapat menyebabkan pencemaran air sungai oleh sisa limbah pemanenan hutan dan peningkatan kandungan lumpur atau sedimentasi sungai. Penelitian Megahan (1977) di Idaho dan Virginia Barat, Amerika Serikat dalam Elias (2002) menunjukkan adanya pengaruh dari kegiatan pemanenan kayu terhadap sedimentasi dan turbiditi pada air sungai. Sedimentasi di Idaho pada DAS kontrol (tidak terganggu) adalah 9,249 ton/tahun/wilayah, DAS terganggu oleh pembangunan dan penyaradan adalah 1.130 ton/tahun/wilayah dan DAS terganggu oleh jalan angkutan kayu adalah 5.500 ton/tahun/wilayah. Sedang turbiditi maksimum di Virginia Barat, diperoleh untuk DAS kontrol adalah 15 ppm, areal dengan tebang pilih dengan limit diameter adalah 5.200 ppm dan untuk areal dengan tebang habis adalah 56.000 ppm.

7. Kecelakaan pekerja banyak

Pekerjaan pemanenan hutan memiliki hubungan yang saling berinteraksi antara manusia, peralatan dan lingkungan. Penggunaan alsinhut besar-besar pada pemanenan hutan sering menyebabkan kecelakaan kerja. Faktor alsinhut yang dirancang sesuai ukuran orang luar negeri yang berukuran besar umumnya posisi instrumen alat kendali tidak sesuai dengan ukuran tubuh pekerja Indonesia yang lebih kecil. Faktor ergonomi dari penggunaan alsinhut ini merupakan penyebab utama kecelakaan kerja karena penggunaan alsinhut tersebut menimbulkan beban kerja yang tinggi. Menurut Idris dan Soenarno (1988) angka frekuensi kecelakaan kerja berkisar antara 95 dan 151 kecelakaan per 1 juta jam kerja/orang/tahun menurut standar ANSI untuk 500 orang tenaga kerja. Sedangkan menurut Priyanto (2000) 
angka kecelakaan kerja yang terjadi pada kegiatan kehutanan di PT. Suka Jaya Makmur pada tahun 1997-1999 cenderung naik, yaitu pada tahun 1997 sebanyak 16 kecelakaan, tahun 1998 sebesar 17 kecelakaan dan tahun 1999 sebesar 22 kecelakaan.

8. Suku cadang tergantung impor

Suku cadang sebagai salah satu faktor pendukung kelancaran operasional alsinhut besar-besar memilliki peranan yang cukup besar, terutama berhubungan dengan biaya pemesanan, biaya penyimpanan, biaya kekurangan maupun sistem yang tepat digunakan untuk mengendalikan persediaan suku cadang. PT. Trakindo Utama sebagai salah satu perusahaan pemasok alat berat kehutanan beserta suku cadang merek Caterpillar yang didatangkan dari Singapura. Banyaknya volume permintaan menyebabkan out stock on hand sehingga perlu dilakukan back order. Sebelum melakukan pemesanaan ke cabang Caterpillar Singapura, maka dilakukan pengecekan terhadap Cabang PT. Trakindo Utama terdekat sehingga waktu tunggu pada suku cadang relatif lama karena tempat pemesanan yang jauh yaitu Jakarta atau cabang PT. Trakindo Utama cabang Singapura (Sugianto, 2003).

9. Penggantian alat sulit

Harga pengadaan alsinhut besar sangat tinggi sehingga pengusaha banyak yang enggan mengganti alat yang sudah tua dengan alat baru. Mereka banyak yang memilih tetap menggunakan alat lama walaupun biaya perbaikan dan pemeliharaan tinggi.

\section{Pencurian kayu makin marak}

Keberadaan alsinhut besar selama ini telah membuka daerah-daerah di luar Pulau Jawa. Keterbukaan daerahdaerah tersebut karena adanya prasarana angkutan, mempermudah para pencuri hasil hutan (kayu) untuk beroperasi. Hal ini telah menjadi masalah nasional yang sampai saat ini belum bisa diatasi.

\section{UPAYAPENGOPTIMALAN PENGGUNAANALSINHUT BESAR}

Untuk masa datang, penggunaan alsinhut besar-besar dalam pembangunan hutan dituntut untuk memenuhi banyak persyaratan agar dapat diterima dan digunakan dalam praktek, yaitu dari segi teknis memungkinkan untuk diaplikasikan (technically possible), dari segi ekonomi dapat menguntungkan (economically feasible) dan dari segi sosial di terima oleh masyarakat (socially acceptable). Sekitar tiga dekade belakangan ini tuntutan tersebut bertambah, yaitu dari segi lingkungan harus ramah lingkungan (environmentally friendly). Dalam bidang kehutanan di Indonesia masih perlu ditambah segi kelembagaan yang harus mantap dan berwibawa dan segi sumberdaya manusia yang harus maju dan berdisiplin tinggi.

\section{A. Segi Teknis}

Peralatan yang digunakan dalam pembangunan hutan harus sesuai dengan ukuran kayu yang ditangani, keadaan lapangan dan tujuan penggunaan kayu. Alat yang terlalu besar akan menimbulkan pemborosan biaya, sedangkan bila terlalu kecil tidak akan mampu menangani kayu. Jenis dan tipe alat yang tidak sesuai dengan kondisi lapangan akan menyulitkan operasi sehingga tidak dapat bekerja dengan baik dan menimbulkan pemborosan dan/atau kerusakan lingkungan. Tujuan penggunaan kayu yang berbeda-beda juga menuntut jenis dan tipe alat yang digunakan agar 
kayu tidak rusak dan nilainya tidak merosot.

Iklim tropis di Indonesia cukup keras terutama karena suhu dan kelembaban yang tinggi dan banyaknya binatang tropis yang mengganggu kelancaran operasi. Alat yang digunakan harus mampu beroperasi pada kondisi seperti itu sehingga tidak banyak biaya untuk perbaikan dan pemeliharaan serta alatnya tidak banyak menganggur.

Masalah kelancaran penyediaan suku cadang mutlak agar operasi tidak sering terganggu. Sebaiknya industri suku cadang dikembangkan di Indonesia. Dari segi kemampuan pelayanan, alat harus mampu melayani seluruh areal hutan yang dipanen dengan mengeluarkan semua kayu yang bernilai ekonomis sehingga tidak ada kayu yang terbuang menjadi limbah (waste).

Dalam hal ukuran, alat-alat pembangunan hutan haruslah sesuai dengan ukuran badan orang Indonesia agar pekerja dapat mengoperasikannya secara optimal, sehat dan tidak menimbulkan kecelakaan. Alat harus mempunyai instrumen pengaman untuk melindungi pekerja dari bahaya dari dalam alat, dari gangguan cuaca buruk dan berbagai obyek di lingkungan kerjanya. Yang juga sangat penting adalah syarat bahwa peralatan harus mudah dioperasikan, mudah diperbaiki dan dipelihara dengan biaya yang wajar.

\section{B. Segi Ekonomi}

Dari segi ekonomi, dituntut biaya pengadaan, perbaikan dan pemeliharaan tidak terlalu mahal. Demikian juga biaya bahan bakar dan suku cadang tidak boros, pada saat diperlukan suku cadang cepat ada agar alat tidak menganggur yang dapat menimbulkan biaya tinggi. Pemasangan alat, pembongkaran, pemindahan dari satu tempat operasi ke tempat operasi lain dan pemasangan kembali di tempat baru hendaknya tidak memakan waktu lama dan biaya tinggi.

\section{Segi Sosial}

Teknologi pembangunan hutan yang digunakan di suatu lokasi operasi haruslah dari jenis dan tipe yang diterima oleh masyarakat sekitar dan bermanfaat bagi mereka. Persyaratan ini sangatlah penting di samping untuk mencegah munculnya gangguan sosial, juga untuk memenuhi rasa keadilan bagi masyarakat untuk ikut berpartisipasi dan menikmati hasil dari suatu kegiatan yang dialkukan di daerah mereka. Untuk masa datang, hal ini makin penting karena masyarakat sudah makin kritis dan berani serta ketersediaan lapangan kerja masih jauh dari cukup.

\section{Segi Lingkungan}

Secara umum meningkatnya kesadaran mengenai dampak lingkungan dari suatu operasi atau penerapan teknologi sudah terjadi sekitar tiga dekade terakhir. Khusus untuk bidang kehutanan, terutama kegiatan pembangunan hutan, peningkatan kesadaran itu baru terjadi sekitar satu dekade terakhir yang berkembang menjadi satu formulasi dan diberi istilah Reduced Impact Logging (RIL). Inti dari RIL tersebut adalah agar setiap operasi pembangunan hutan harus direncanakan secara intensif dan implementasinya diawasi secara ketat sehingga operasi dapat berjalan efektif dengan tingkat gangguan terhadap tegakan hutan dan tanah hutan serta gangguan lainnya berada pada tingkat minimal (Dykstra, 2001; FAO, 2004). Perencanaan dimaksud di sini termasuk pemilihan jenis dan tipe alat serta perencanaan berbagai aspek terkait operasi pembangunan hutan di lapangan. Terlihat di sini tuntutan akan jenis dan tipe peralatan yang digunakan haruslah yang mempunyai dampak kerusakan terhadap hutan dan tanah yang minimal. 


\section{E. Segi Kelembagaan}

Untuk menjamin pemilihan teknologi yang digunakan dan cara pengoperasiannya di lapangan dapat berjalan dengan benar, diperlukan adanya sistem kelembagaan yang jelas wewenangnya menangani masalah teknologi pembangunan hutan. Lembaga inilah yang menetapkan standar-standar dan peraturan perundangan dalam pengadaan, pengoperasian dan lain-lain yang perlu serta memberi sanksi atas pelanggaran yang mungkin terjadi. Lembaga ini jugalah yang terus menerus menegakkan pelaksanaan peraturan perundangan (law enforcement) dalam pembangunan hutan agar kerugian akibat gangguan kerusakan hutan dan tanah hutan, kerugian karena kesalahan penanganan produk dan sebagainya dapat dihindari atau setidaknya diminimalkan.

\section{F. Segi Sumberdaya Manusia}

Agar praktek pembangunan hutan di Indonesia berjalan baik, diperlukan kesadaran dan kemauan dari para penentu kebijakan akan pentingnya pelaksanaan pembangunan hutan berjalan dengan baik. Untuk tingkat pelaksana, diperlukan perencana, operator, mekanik, penyelia, manajer dan pimpinan yang ahli di bidangnya. Untuk itu diperlukan lembaga pendidikan dan pelatihan yang secara berkelanjutan membangun dan meningkatkan kemampuan SDM dan menyampaikan teknologi baru yang sesuai kepada yang memerlukan. Untuk mengembangkan ilmu pengetahuan dan teknologi (iptek), perlu dikembangkan lembaga kelitbangan yang kuat yang secara terusmenerus mencari perbaikan teknologi yang sudah ada dan melakukan koreksi atas kesalahan yang timbul. Salah satu tuntutan lain lagi adalah disiplin yang tinggi dari semua pihak terkait agar pembangunan hutan berjalan efektif dan efisien serta berkelanjutan.

\section{KESIMPULANDANSARAN}

Dari uraian berbagai aspek penggunaan alat dan mesin dalam pembangunan hutan di Indonesia, dapat dikemukan beberapa kesimpulan berikut:

1. Pengertian alat dan mesin besar dalam pembangunan hutan (alsinhut) adalah alat dan mesin yang mempunyai tenaga penggerak berkekuatan $50 \mathrm{HP}$ atau lebih. Alsinhut di Indonesia umumnya masuk kategori tersebut.

2. Keuntungan penggunaan alsinhut besar-besar cukup banyak, antara lain : (1) mampu menangani produk (kayu) dalam jumlah besar, (2) proses produksi cepat dan tepat waktu, (3) mampu menangani kayu-kayu yang besar, panjang dan berat, (4) mampu menghadapi medan operasi pembangunan hutan yang berat, (5) membuka lapangan kerja, (6) bisnis suku cadang dan bahan pendukung berkembang, (7) meningkatkan devisa negara, (8) meningkatkan ketrampilan tenaga kerja dan (9) membuka wilayah yang tadinya tertutup.

3. Kerugian penggunaan alsinhut besar-besar juga banyak, antara lain : (1) biaya produksi tinggi, (2) kerusakan tegakan tinggal tinggi, (3) luas keterbukaan tanah dan tajuk hutan tinggi, (4) erosi tanah hutan tinggi, (5) pemadatan tanah hutan tinggi, (6) pencemaran air sungai tinggi, (7) kecelakaan pekerja tinggi, (8) suku cadang tergantung impor, (9) penggantian alat sulit dan (10) pencurian kayu marak. 
4. Upaya mengoptimalkan penggunaan alsinhut besar dapat dilakukan dengan cara memenuhi berbagai tuntutan persyaratan pengoperasian peralatan, antara lain dari segi teknis harus yang memungkinkan untuk dilaksanakan, dari segi ekonomi dapat menguntungkan, dari segi sosial dapat diterima, dari segi lingkungan harus ramah lingkungan, dari segi kelembagaan harus mantap dan berwibawa dan dari segi sumberdaya manusia harus maju dan berdisiplin tinggi.

5. Disarankan agar dalam menggunakan alsinhut besar-besar dalam pembangunan hutan, semua pihak terkait, baik penentu kebijakan maupun pelaksana, memahami betul semua persyaratan tersebut pada butir 4 dan merealisasikannya dalam praktek pembangunan hutan agar manfaat dari teknologi alsinhut dapat diambil sedang kerugian yang ditimbulkannya dapat diminimalkan.

\section{DAFTAR PUSTAKA}

Anonim. 1988. Caterpillar Performance Handbook. Edition 19. Caterpillar Inc. Pearia, Illinois.

Komatsu D80 buldoser leaflet. Komatsu Ltd. Tokyo.

Brainer, L.D., R.A.Kepner and D.L. Berger. 1960. Principles Of farm Machinery. John Wiley and Sons, Inc. New York.

Dulsalam, Sukanda dan I. Sumantri. 1989. Kerusakan tegakan tinggal akibat penyaradan dengan traktor pada berbagai tingkat kerapatan tegakan. Jurnal Penelitian Hasil Hutan 6(6):349352. Pusat Penelitian dan Pengembangan Teknologi Hasil Hutan. Bogor.

Departemen Kehutanan. 1990. Statistik Kehutanan Indonesia 1990/1991. Departemen Kehutanan. Jakarta.

Dulsalam dan Sukadaryati. 2001. Produktivitas dan biaya penyaradan kayu dengan kerbau di Jambi. Buletin Penelitian Hasil Hutan 19(3):147-164. Pusat Penelitian dan Pengembangan Teknologi Hasil Hutan. Bogor.

Dykstra, D.P. 2001. Reduced impact logging : concepts and issues. Paper at International Conference on the Application of Reduced Impact Logging to Advance Sustainable Forest Management, held in Kuching, Sarawak, February 26 - March 1, 2001. pp. 1 - 10.

Elias. 2002. Reduced impact logging. Institut Pertanian Bogor Press. Institut Pertanian Bogor. Bogor.

FAO. 2004. Reduced Impact Logging in Tropical Forest Mangement. Harvesting and Engineering Working Paper No. 1. Forestry Department, FAO, Rome.

Frederiksen, P.W. 1970. Erosion and sedimentation following road construction and timber harvest on unstable soils in three small western Oregon watersheds. USDA Forest Service Res. Paper PNW. 104.

Gill, W.R.1959. Soil compaction by traffic. Agriculture Engineering 40(7):392, 4004001.

Idris, M.M. 1987. Pengaruh penyaradan kayu dengan traktor berban ulat terhadap kerusakan tegakan tinggal, penggeseran serta pemadatan tanah hutan. Tesis Program Pasca Sarjana, Institut Pertanian Bogor. Bogor. Tidak diterbitkan. 
Penggunaan Alat dan Mesin Besar-besar Dalam. .. DjabanTinambunan \& Yuniawati

Idris, M.M. dan Soenarno. 1988. Kecelakaan kerja dalam kegiatan eksploitasi hutan di Kalimantan Tengah. Jurnal Penelitian Hasil Hutan 5(1):31-36. Pusat Penelitian dan Pengembangan Teknologi Hasil Hutan. Bogor.

Idris, M.M. 1996. Dampak penebangan dan penyaradan di hutan produksi terbatas terhadap erosi tanah, keadaan iklim mikro dan permudaan alam. Disertasi Doktor. Program Pasca Sarjana, Institut Pertanian Bogor. Bogor. Tidak diterbitkan.

Manan, S. 1994. Kerusakan lingkungan akibat pembalakan dan cara-cara menanggulanginya. Paper pada penataran Manajer Logging pada 13-17 Desember 1992 di Fakultas Kehutanan, Institut Pertanian Bogor. Bogor.

Rahmawati, I. 2002. Pengaruh intensitas penyaradan kayu oleh traktor trehadap kepadatan tanah dan pertumbuhan Acacia mangium dan Paraserianthes falcataria. Skripsi Fakultas Kehutanan, Institut Pertanian Bogor. Bogor. Tidak diterbitkan.

Retnowati, E. 2004. Dampak kegiatan penyaradan dalam sistem TPTI terhadap sifat-sifat tanah di hutan produksi alam di Kalimantan Timur. Jurnal Penelitian Hutan dan Konservasi Alam 1(1):34-44. Pusat Penelitian dan Pengembangan Hutan dan Konservasi Alam. Bogor.

Sastrodimedjo, R.S., R.S. Simarmata dan Soewito. 1973. Produktivitas dan biaya peralatan mekanis pada eksploitasi jenis-jenis meranti di Sumatera. Laporan No. 15. Lembaga Penelitian Hasil Hutan. Bogor.

Soedjatmiko, 1974. Masalah Penggunaan Traktor Dalam Budidaya Pertanian Di Indonesia. Kertas Kerja Dalam Seminar Penerapan Teknologi Madia Pada Industri Pertanian. Fakultas Teknologi Pertanian, Institut Pertanian Bogor. Bogor.

Sastrodimedjo, R.S., J. Thaib, A. Sianturi dan S.R. Simarmata. 1977. Produktivitas dan biaya alat eksploitasi mekanis pada beberapa permasalahan hutan di Maluku. Laporan No. 97. Lembaga Penelitian Hasil Hutan. Bogor.

Sianturi, A. dan D. Tinambunan. 1984. Studi kasus pemuatan kayu bulat di empat perusahaan eksploitasi hutan di Jambi. Laporan No. 170. Pusat Penelitian dan Pengembangan Hasil Hutan. Bogor.

Sukadaryati, Dulsalam dan M. Sinaga. 2002. kerusakan tegakan tinggal, keterbukaan lahan, penggeseran tanah dan biaya pada penyaradan terkendali. Buletin Penelitian Hasil Hutan 20(5):379-399. Pusat Penelitian dan Pengembangan Hasil Hutan. Bogor.

Suhartana, S. 2003. Penyaradan terkendalai untuk meminimasi kerusakan hutan dan biaya di hutan alam. Prosiding Seminar Nasional MAPEKI V di Bogor tanggal 30 agustus 1 September 2002. Pusat Penelitian dan Pengembangan Hasil Hutan. Bogor.

Sugianto, W. 2003. Analisis pengendalian persediaan suku cadang oil filter dan fuel filter traktor D7G dan wheel loader 966C di PT. Trakindo Utama Kantor Cabang Samarinda dan Banjarmasin. Skripsi. Fakultas Kehutanan, Institut Pertanian Bogor. Bogor. Tidak diterbitkan.

Thaib, J. 1985. Kerusakan tegakan sisa akibat eksploitasi hutan dengan sistem traktor dan high lead. Jurnal Penelitian Hasil Hutan 2(4):14-18. Pusat penelitian dan Pengembangan Hasil Hutan. Bogor. 